\title{
A Case Study on Students' Concept Images of the Uniform Convergence of Sequences of Continuous Functions ${ }^{1}$
}

\author{
JEONG, Moonja \\ Department of Mathematics, The University of Suwon, \\ Gyeonggi-do 445-743, Korea; E-mail: mjeong@suwon.ac.kr \\ KIM, Seong-A* \\ Department of Mathematics Education, Dongguk University, \\ Gyeongju 780-714, Korea; Email: sakim@ dongguk.ac.kr
}

(Received June 7, 2013; Revised June 22, 2013; Accepted June 29, 2013)

\begin{abstract}
In this research, we investigated students' understanding of the definitions of sequence of continuous functions and its uniform convergence. We selected three female and three male students out of the senior class of a university and conducted questionnaire surveys 4 times. We examined students' concept images of sequence of continuous functions and its uniform convergence and also how they approach to the right concept definitions for those through several progressive questions. Furthermore, we presented some suggestions for effective teaching-learning for the sequences of continuous functions.
\end{abstract}

Keywords: concept image, concept definition, sequence of continuous functions, the uniform convergence, the point-wise convergence, the $\epsilon-N$ definition, the $\epsilon-N$ proof MESC Classification: I25, D75, C35

MSC2010 Classification: 97D40

\section{INTRODUCTION}

The college level Calculus and Set Theory courses precede the Advanced Calculus course in general in the learning of mathematics majors in the university. Students of the

1 This paper will be presented at KSME 2013 International Conference of Mathematics Education on Creativity and Giftedness at Mokwon Univ., Doan-dong, Seo-gu, Daejeon 302-729, Korea; August 9-10, 2013.

* Corresponding author 
mathematics department are introduced to symbolized, formal, and abstract major subjects of college level through learning a set theory. Students start to lay a foundation for the major subject through training of logical thinking by means of symbols in the study of Set Theory. If students are lacking in logical thinking about the various theories in the subject of Set Theory, they would have difficulty in learning a subject which requires a rigorous and formal thinking in terms of an existential quantifier $\exists$, an universal quantifier $\forall$, and a symbol $\epsilon$ in the upper class subject, Advanced Calculus in particular, with which this research is concerned. In this research, we investigated students' understanding of sequences of continuous functions through analyzing the concept images that students acquired.

It is inquired whether the pictures play an intrinsic role as concept images through the investigations and analyses on the convergence of the sequences of continuous functions (Stoll, 2001; Munkres, 1975) and its geometric concept images. In this research, we use the terminologies, 'concept image' and 'concept definition' according to Vinner (1983), and we mean further clarification of the concept image through inferences employing pictures by the intrinsic role of the pictures. The concept image (Park, 1993) consists of the denotation and connotation associated with the concept and its own mental picture which stands for all the representations related with it formed in the mind of an individual, that is, a collection of picture, symbol, diagram, and graph.

Dieudonne (1969) intentionally tried not to use pictures asserting that mathematics should be founded on the axiomatic methods not depending on geometrical intuitions. Many of the contemporary mathematicians insisted the incompatibility of the mathematical rigor and the employment of pictures based on the geometrical intuitions. However, considering the assertions (Brown, 1999) that pictures still brought forth crucial ideas for the major mathematical discoveries, we think that the use of pictures may not be excluded in the learning of plane curves. But, after recognizing the limitations of the geometrical intuition by the existence of a non-differentiable function which is continuous everywhere due to Weierstrass, the $\epsilon-\delta$ proof due to Bolzano and Weierstrass has come to be regarded as a rigorous way of explaining continuity of functions in the mathematical community. Nevertheless, when we investigate students' understanding of the mathematical concepts, it is important for a better teaching-learning of mathematical concepts explained in terms of $\epsilon-\delta$ or $\epsilon-N$ to observe the personal images which learners have on the $\epsilon-\delta$ definition and $\epsilon-\delta$ proof. This research revealed that most of students (female students in particular) are inclined to form their concept images by using geometrical intuitions, namely pictures in the process of 'personalization and depersonalization' (Hwang, 2011) of their knowledge. It may also be because the geometrical intuitions tell us what is important, interesting, and easy to get as asserted by Woo (2005). 
Students who participated in this research lacked in understanding the sequences of continuous functions since the concept of uniform convergence of sequences is contained in the later chapters of the textbook of Advanced Calculus used in their department and usually tended to be treated inadequately for lack of time. Therefore, it may be regarded as an appropriate research subject to investigate students' understanding of the sequences of continuous functions through their concept images. We also expected students had a chance to get right concept definition through participation in our surveys. Furthermore, we wanted to grasp students' difficulty in understanding the concept of uniform convergence at their level since we found that many of math students seem to share the same difficulty in the classes of Advanced Calculus.

In this research, we investigated students' concept images in the learning of convergence of sequences of continuous functions by suggesting concrete questions on the definitions and examples of the sequences to identify how students come to understand the rigorous $\epsilon-\delta$ method through exploiting geometrical intuitions. For this research, we selected students who finished the course of Advanced Calculus and General Topology, and conducted and analyzed surveys. We developed stepwise questionnaires on the concepts of sequences of continuous functions for which students used to have cognitive difficulties in the classes of Advanced Calculus or General Topology, and conducted surveys four times. By analyzing students' responses on the questionnaires, we examined their understanding and misconceptions about the point-wise convergence and uniform convergence of sequences of continuous functions. We analyzed the elements which caused students' cognitive difficulties, and made suggestions for improving teaching-learning of the convergences. As students participated in the surveys consisted of male and female students, we investigated the differences in ways of approaching the concept of sequences of continuous functions between the male and female students through grouping them by gender and conducting surveys separately. The results of the surveys are discussed for references in teaching-learning of sequences of continuous functions although they cannot be generalized due to the small number of the participants.

\section{THEORETICAL BACKGROUND}

The study on the sequences of functions and power series of functions originated from the study of power series representations of functions. In 17th century, N. Mercator expressed the function $\ln (1+x)$ as a power series, and J. Gregory expressed the transcendental functions like $\arctan x, \arcsin x$ as power series. In 19th century, as Cauchy produced outstanding achievements in the theory of sequences and series, Weierstrass 
gave excellent results in the researches on the theory of sequences and series of functions. Also, Weierstrass distinguished carefully the convergence of sequences or series from that of the sequences or series of functions, and showed that the concept of uniform convergence is an essential assumption to preserve the continuity and integrability of functions. Mathematicians before 19th century often had faulty notions on sequences of functions, series of functions, and problems involving interchange of limits. Even Cauchy had proved erroneously a theorem whose gist was that the limit of a convergent sequence of continuous functions was continuous (Stoll, 2001, p.317).

Cho (2011) suggested a teaching plan to diminish the misconceptions frequently occurring in the use of symbols $\epsilon$ and $\delta$ by visualizing the teaching-learning of the limit of functions via $\epsilon-\delta$ method with the help of CAS graphing calculator. By obtaining the corresponding value of $\delta$ for a given $\epsilon$ with CAS graphing calculator, students are induced to understand their relations and the limit of the functions further. Seo (2001) and Kim (2011) summarized the known mathematical theories on the point-wise convergence and uniform convergence of sequences of continuous functions, not concerned with teaching design in their research. There are no precedent researches on teaching-learning of concepts of the convergence of sequences of functions at a college level. As mentioned above, the research of Cho (2001) is known as a teaching-learning design through a visualization of the limit of functions.

The definitions of point-wise convergence and the uniform convergence of sequences of functions are briefly discussed here; Let $\boldsymbol{D} \subseteq \mathbb{R}$ and a function $\boldsymbol{f}_{\boldsymbol{n}}: \boldsymbol{D} \rightarrow \mathbb{R}$ be defined for each $\boldsymbol{n} \in \mathbb{N}$ where $\mathbb{R}$ is the set of real numbers. Then the set $\left\{\boldsymbol{f}_{\boldsymbol{n}}\right\}$ of such functions is called a sequence of real functions. If $\left\{\boldsymbol{f}_{\boldsymbol{n}}(\boldsymbol{x})\right\}$ converges for each $\boldsymbol{x} \in \boldsymbol{D}$ when $\boldsymbol{n} \rightarrow \infty$, we say that $\left\{\boldsymbol{f}_{\boldsymbol{n}}\right\}$ converges point-wise. In this case, by the uniqueness of limit, the limit function $f: D \rightarrow \mathbb{R}$ is defined by $f(x)=\lim _{n \rightarrow \infty} f_{n}(x), x \in D$. By the $\epsilon-N$ definition of limit, if there exists a positive integer $N=N(x, \epsilon)$ for each $x \in D$ and for an arbitrarily given $\boldsymbol{\epsilon}>\mathbf{0}$ such that $\left|\boldsymbol{f}_{\boldsymbol{n}}(\boldsymbol{x})-\boldsymbol{f}(\boldsymbol{x})\right|<\boldsymbol{\epsilon}$ for all $\boldsymbol{n} \geq \boldsymbol{N}$, then we say that $\left\{\boldsymbol{f}_{\boldsymbol{n}}\right\}$ converges point-wise to $\boldsymbol{f}$, and denoted by $\boldsymbol{f}_{\boldsymbol{n}} \rightarrow \boldsymbol{f}$. The additional condition of uniform convergence is required to guarantee continuity of the limit function of a (point-wise) convergent sequence of continuous functions. If for a function $f: D \rightarrow \mathbb{R}$, there exists a positive integer $\boldsymbol{N}=\boldsymbol{N}(\boldsymbol{\epsilon})$ for an arbitrarily given $\boldsymbol{\epsilon}>\mathbf{0}$ such that $\left|\boldsymbol{f}_{\boldsymbol{n}}(\boldsymbol{x})-\boldsymbol{f}(\boldsymbol{x})\right|<\boldsymbol{\epsilon}$ for all $\boldsymbol{n} \geq \boldsymbol{N}$ and for all $\boldsymbol{x} \in \boldsymbol{D}$, then we say that $\left\{\boldsymbol{f}_{\boldsymbol{n}}\right\}$ converges uniformly to $\boldsymbol{f}$. If a sequence of continuous functions defined on a set $\boldsymbol{D}$ converges uniformly, the limit function is continuous. In the case when the set $\boldsymbol{D}$ is a closed interval, a given sequence of continuous functions converges uniformly if its limit function is continuous (Stoll, 2001). 


\section{RESEARCH METHOD}

\section{Participants and procedure}

We selected as participants in this research 6 students whose grades belong to the top 20 percent of the senior class in the mathematics department in S university. We call the 3 male students of the participating students as A, B, C, and the remaining 3 female students as D, E, F. For the purpose of investigating any differences in the results of surveys by gender, students were separated into the male and female groups which we called $\mathrm{M}$ and $\mathrm{F}$ respectively and the surveys were conducted separately. The surveys were conducted 4 times from Sept. 8th to Nov. 10th in 2010 as shown in Table 1.

Table 1. The schedule of questionnaires

\begin{tabular}{c|l|l|c|}
\hline & Date and time & \multicolumn{1}{|c|}{ Contents of questionnaires } & Note \\
\hline 1 st & $\begin{array}{l}\text { Sept. 15th. } \\
\text { (M) 5th period, } \\
\text { (F) 8th period }\end{array}$ & $\begin{array}{l}\text { Students' background and learning attitude. Stu- } \\
\text { dents' understanding of definitions of se- } \\
\text { quences of continuous functions. }\end{array}$ & 1 hour \\
\hline 2nd & $\begin{array}{l}\text { (M) Sept. 29th. } \\
\text { (F) Oct. 6th. }\end{array}$ & $\begin{array}{l}\text { Students' concept images of sequences of contin- } \\
\text { uous functions. }\end{array}$ & 1 hour \\
\hline 3rd & $\begin{array}{l}\text { Oct. 13th. } \\
\text { (M) 5th period, } \\
\text { (F) 8th period }\end{array}$ & $\begin{array}{l}\text { Students' understanding of convergence of se- } \\
\text { quences of continuous functions. }\end{array}$ & 1 hour \\
\hline \multirow{3}{*}{$\begin{array}{l}\text { Nov. 10th. } \\
\text { (M) 5th period, } \\
\text { (F) 8th period }\end{array}$} & Students'visual images of sequences of continu- \\
ous functions. & 1 hour \\
\hline
\end{tabular}

\section{Research contents}

\subsection{Students'background in the subject of Advanced Calculus}

Students participating in this study took the same course in the 2nd semester of 2008 and learned the following materials from 'Introduction to Real Analysis' by Stoll (2001) which was the main textbook for the course; in chapter 4, 'limits and continuity: limit of a function, continuous functions, uniform continuity, monotone functions and discontinuities,' and in chapter 8, 'sequences and series of functions: point-wise convergence and interchange of limits, uniform convergence, uniform convergence and continuity.' Therefore, the background of students may be deemed equal on some of the contents of Advanced Calculus, namely, on the limits and convergence of continuous functions and se- 
quences of continuous functions with which we are concerned in this research. When students took the course in the 2nd semester of 2008, the contents from chapter 4 through 8 were treated in the class. In fact, the contents in chapter 4 were delivered in the 1 st semester, however, were repeated at the beginning of the 2 nd semester. Since the contents in the last chapter 8 were not treated faithfully for lack of time, the understanding of students participating in this research seemed insufficient in the concept of uniform convergence of sequences of continuous functions. Therefore, it may be considered as an appropriate theme to investigate students' understanding of the present subject in response to the necessity of complementing it. In addition, it is a significance of this research to grasp students' difficulty in understanding the concept of uniform convergence at their level, since the researchers have experienced that many of students would go through difficulty in this concept while giving lectures of Advanced Calculus.

\subsection{First Questionnaire and analysis}

\section{1) Survey on students' background and learning attitude}

The participating senior students were grouped into A, B, C (male students) and D, E, $\mathrm{F}$ (female students), and the results of the survey are summarized in Table 2. All of the 6 participating students took almost all courses of the major subjects which are opened by the mathematics department including subjects of Set Theory, Advanced Calculus 1, Advanced Calculus 2, Vector Calculus, Differential Geometry, General Topology 1, General Topology 2, and Complex Variables 1.

In Table 2, (1) represents 'very much', (2), 'somewhat', (3), 'average', (4), 'not really', except for the questions 5-1, 5-2, 7-1, and 7-2 for which (1) represents $\mathrm{A}+$, (2), $\mathrm{A}_{0}$, (3), $\mathrm{B}+$, and (4), $\mathrm{B}_{0}$, respectively. The average shown in Table 2 is obtained by weighting 5, 4, 3, and 2 points for (1), (2), (3), and (4), respectively. The results show that students participating in the survey generally prefer General Topology to Advanced Calculus, and got better grades in General Topology. While students' understanding of sequences of continuous functions is normal on average, their conceptual understanding of limit of sequences of continuous functions is closer to 'good acquaintance'. The geometric approach is given a little higher preference to the analytic approach, and students responded that when encountering a function, they try to associate a graph of it. In the following, students' responses to Questions 9 and 10 are described.

Question 9. Do you prefer geometric intuitions to an analytic approach? If so, what is the reason?

A: I prefer an analytic approach involving some analyses. 
B-F: I prefer a geometric approach since geometrical intuitions facilitate understanding.

Question 10. Describe your present concept image of a sequence of functions.

Students vaguely associate properties and limits of sequences of functions as well as the definitions of it.

A: The rules of sequences of numbers and properties of functions will show up compositely.

B: A function is given to some sequence. Do the sequence have limit?

C: A function itself becomes the sum of a sequence which is connected with it in a certain way.

D, E: A sequence each of whose terms is a function.

F: A sequence which make use of functions.

Table 2. First Questionnaire-students' background and learning attitude

\begin{tabular}{|c|c|c|c|c|c|c|c|c|}
\hline & Questions & $\mathrm{A}$ & $\mathrm{B}$ & $\mathrm{C}$ & $\mathrm{D}$ & $E$ & $\mathrm{~F}$ & $*$ \\
\hline 1 & $\begin{array}{l}\text { I am familiar with the concept of } \\
\text { continuous functions. }\end{array}$ & (2) & (3) & (2) & (2) & (1) & (1) & 4.2 \\
\hline 2 & $\begin{array}{l}\text { I am familiar with the concept of } \\
\text { sequences of continuous functions. }\end{array}$ & (3) & (3) & (3) & (3) & (3) & (3) & 3 \\
\hline 3 & $\begin{array}{l}\text { I am familiar with the concept of } \\
\text { limit of sequences of functions. }\end{array}$ & (2) & (2) & (2) & (3) & (2) & (3) & 3.7 \\
\hline 4 & $\begin{array}{l}\text { I like the subject of Advanced } \\
\text { Calculus. }\end{array}$ & (1) & (3) & (3) & (2) & (2) & (3) & 3.7 \\
\hline $5-1$ & $\begin{array}{l}\text { What is your grade in Advanced } \\
\text { Calculus 1? }\end{array}$ & (2) & (3) & (2) & (1) & (2) & (2) & 4 \\
\hline $5-2$ & $\begin{array}{l}\text { What is your grade in Advanced } \\
\text { Calculus 2? }\end{array}$ & (2) & (4) & (2) & (1) & (2) & (3) & 3.7 \\
\hline 6 & $\begin{array}{l}\text { I like the subject of General } \\
\text { Topology. }\end{array}$ & (1) & (3) & (2) & (2) & (2) & (2) & 4 \\
\hline $7-1$ & $\begin{array}{l}\text { What is your grade in General } \\
\text { Topology } 1 \text { ? }\end{array}$ & (2) & (2) & (1) & (1) & (2) & (2) & 4.3 \\
\hline $7-2$ & $\begin{array}{l}\text { What is your grade in General } \\
\text { Topology } 2 \text { ? }\end{array}$ & (1) & (3) & (1) & (1) & (3) & (2) & 4.2 \\
\hline 8 & $\begin{array}{l}\text { When encountering a function, } \\
\text { I try to associate its graph first of } \\
\text { all. }\end{array}$ & (2) & (1) & (1) & (2) & (2) & (4) & 4 \\
\hline \multirow{2}{*}{9} & \multirow{2}{*}{$\begin{array}{l}\text { Do you prefer geometric intuitions } \\
\text { to an analytic approach? } \\
\text { If so, what is the reason? }\end{array}$} & (4) & (1) & (2) & (2) & (2) & (2) & 3.8 \\
\hline & & & & & & & & \\
\hline 10 & \multicolumn{8}{|c|}{ What is your present concept image of sequences of functions? } \\
\hline
\end{tabular}

*Average 
2) Students' understanding of concepts of sequences of continuous functions

A questionnaire survey in Table 3 was conducted especially on the definition of a sequence of continuous functions.

Table 3. First questionnaire-definitions of a sequence of continuous functions

Question 1. Write down the definition of a sequence of continuous functions.

Question 2. Write down the definition of a limit of a sequence of functions.

Question 3. Describe freely the visual image you have in your mind on the limit of a sequence of continuous functions.

For Question 1, students replied on the definition of sequences of continuous functions. Students A, D, E, and F replied that every sequence consisting of continuous functions is a sequence of continuous functions. Student B replied that a function exists for a sequence which varies in terms of $\mathrm{n}$, and that each sequence of functions is connected, not separated within itself. (Student $\mathrm{C}$ did not answer).

For Question 2 asking the definition of the limit of a sequence of functions, student D alone answered by using the $\epsilon-N$ definition; $f_{n}(x) \rightarrow f$ is defined by the existence of suitable $M$ such that $\left|f_{n}(x) \rightarrow f\right|<\epsilon$ for $\forall \epsilon$ and for $\forall n \geq M$. Student $C$ did not answer, and the rest of students described the meaning of 'limit' in words as 'the value to which a sequence converges (student B's answer)'. For Question 3 asking students' visual image on the limit of a sequence of continuous functions, female students explain more geometrically than male students. It is worth a careful note that female students tried a geometrical approach to the sequence of continuous functions. Students' responses are as follows:

A: A bouquet, $f_{n}(x)=\frac{n x}{n+1}$ (see Figure 1).

B: Terminologies like 'function and sequence' sound difficult, and might give various values. But, the concept of limit gives an image of many points accumulated at one place.

C: Representing $f_{n}(x)$ graphically, it sounds as if most of the graphs of functions gather nearby except finite number of functions.

$\mathrm{D}, \mathrm{F}$ : For $f_{n}(x)=\frac{x}{n}, \lim _{n \rightarrow \infty} f_{n}(x)=0$. (students drew graphs of sequence of functions)

E: For $f_{n}(x)=\frac{n x}{n+1}, \lim _{n \rightarrow \infty} f_{n}(x)=x$. For $f_{n}(x)=n x, \lim _{n \rightarrow \infty} f_{n}(x)$ does not exist (see Figure 2). 


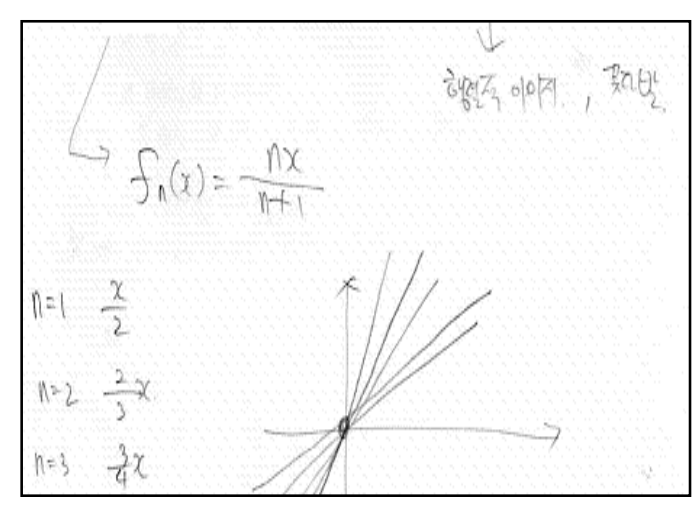

Figure 1. Image of a sequence of continuous functions by student A

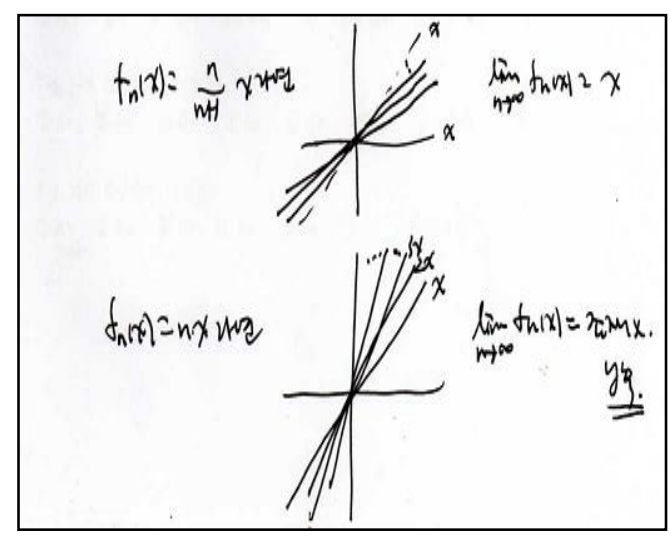

Figure 2. Image of a sequence of continuous functions by student $\mathrm{E}$

\subsection{Second questionnaire and analysis}

We investigated students' concept images on the convergence of sequences of continuous functions according to the second questionnaire (see Table 4).

\section{1) Students' responses for Question 1}

Students were asked to answer freely by using graphs or mathematical formulas or words on the meaning of the convergence of a sequence of continuous functions $\left\{f_{n}\right\}$ to $f$. Most of students described the definition of point-wise convergence. Male students, A, $\mathrm{B}$ and $\mathrm{C}$ described the $\epsilon-N$ definition of point-wise convergence. Student B additionally drew a graph, but it was a wavy graph representing uniform convergence (see Figure 3). On the other hand, the female students D, E, and F sketched graphs first, and then described the $\epsilon-N$ definition of point-wise convergence (see Figure 4). Recalling graph- 
ically the concept images of the point-wise convergence, female students formally described the $\epsilon-N$ definition.

Table 4. Second questionnaire

Question 1. Students' concept images on the convergence of sequences of continuous functions.

1. A sequence of functions $\left\{f_{n}\right\}$ consisting of continuous functions $f_{n}$ defined on a given set $E$ is called a sequence of continuous functions on $E$. What does it mean that $\left\{f_{n}\right\}$ converges to a function $f$ ? Give your answer freely by using graphs or mathematical formulas or words.

Question 2. Students' understanding of point-wise and uniform convergence of a sequence of continuous functions.

1. Find examples of a sequence of continuous functions $\left\{f_{n}\right\}$ which converge point-wise to $f$. (Also draw graphs.) Observing examples, write down the definition of point-wise convergence.

2. Find examples of a sequence of continuous functions $\left\{f_{n}\right\}$ which converge uniformly to $f$. (Also draw graphs.) Observing examples, write down the definition of uniform convergence.

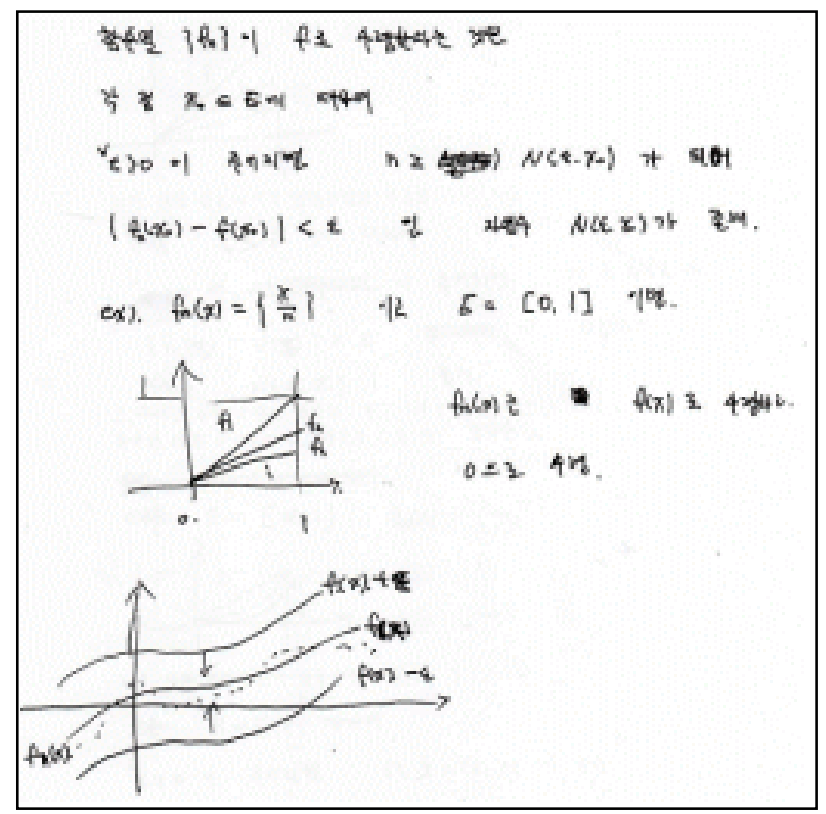

Figure 3. Concept image of convergence of a sequence of functions by student B 


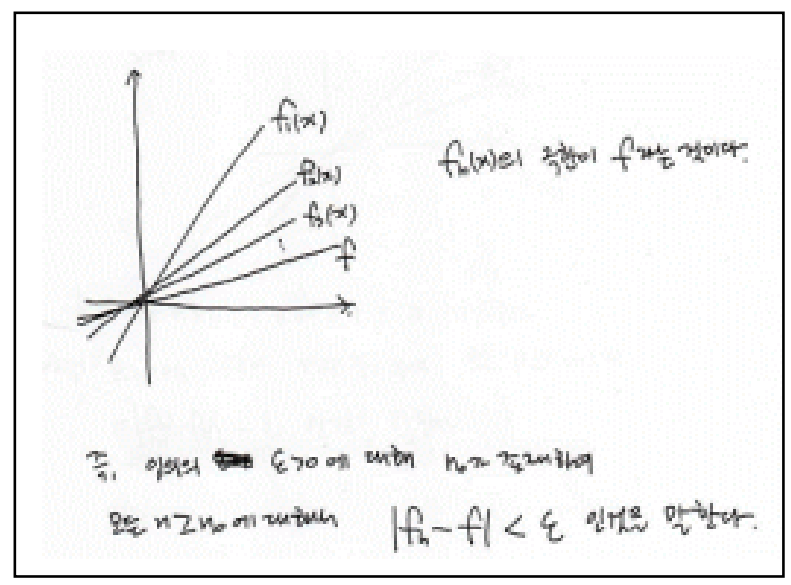

Figure 4. Concept image of convergence of a sequence of functions by student D

\section{2) Students' responses for Question 2}

Male students did not understand difference between the point-wise convergence and the uniform convergence. However, they kept the terminologies in memory. Female students did not remember the meaning of uniform convergence since they learned it in the second year. Therefore, we explained the definition of uniform convergence in detail and let students answer the questionnaire again. By this help, students were thought to have grasped the definition on the whole though they made errors in statements using symbols being unaware of the differences in the meaning of statements depending on the location of 'all $x$ ' $(\forall x)$. The examples which students found are shown in Table 5.

Table 5. Examples of point-wise convergence and uniform convergence

\begin{tabular}{|c|c|c|}
\hline Student & Point-wise convergence & Uniform convergence \\
\hline A & $\begin{array}{l}E=[0,1] \rightarrow \mathbb{R}, f_{n}(x)=x^{n} \\
\text { limit function } f= \begin{cases}0, & x=0 \\
1, & x=1\end{cases} \end{array}$ & $E=[0,1] \rightarrow \mathbb{R}, f_{n}(x)=x^{n}$ \\
\hline B & $E=[0,1], \quad f_{n}(x)=\frac{x}{n}$ & $E=[0,1], f_{n}(x)=x^{n}$ \\
\hline $\mathrm{C}$ & $\begin{array}{l}f_{n}:[0,1] \rightarrow \mathbb{R}, f_{n}(x)=x^{n} \\
\text { converges point-wise to } \\
f:[0,1] \rightarrow \mathbb{R}, f=0\end{array}$ & $\begin{array}{l}f_{n}:[0,1] \rightarrow \mathbb{R}, f_{n}(x)=\frac{x}{n} \text { con- } \\
\text { verges uniformly to } \\
f:[0,1] \rightarrow \mathbb{R}, f=0\end{array}$ \\
\hline $\mathrm{D}$ & $f_{n}(x)=\frac{n}{n+1} x$ & $f_{n}(x)=\sin x+\frac{1}{n}$ \\
\hline $\mathrm{E}$ & $f_{n}(x)=\frac{x}{n}$ & $f_{n}(x)=x+\frac{1}{n}$ \\
\hline $\mathrm{F}$ & $f_{n}(x)=\frac{x}{n}$ & $f_{n}(x)=\frac{1}{n}$ \\
\hline
\end{tabular}


Students had no problem finding examples of point-wise convergent sequences of functions. For examples of point-wise convergence and uniform convergence of sequences of functions, male students $\mathrm{A}, \mathrm{B}$, and $\mathrm{C}$ represented the domain $E$ of the functions concretely. From the examples of uniformly convergent sequences of functions that students constructed in Table 5, we can see that male students A and B showed a lack of preunderstanding of uniform convergence, while student $C$ found a correct example but there was some doubt that he had figured out the meaning of uniform convergence by his definition of uniform convergence on Table 6 .

Table 6. Students' understanding of the definition of uniform convergence

\begin{tabular}{|c|c|c|}
\hline Student & Definition of uniform convergence & Analysis \\
\hline A & 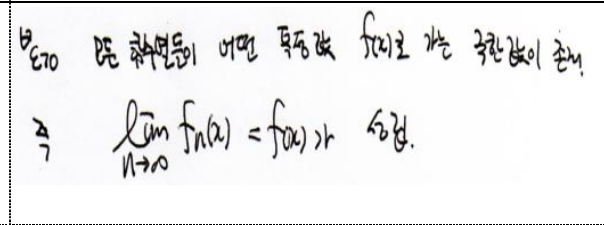 & $\begin{array}{l}\text { With the misconception about } \\
\text { 'every', the student A started with } \\
\varepsilon, \text { but didn't develop any more. } \\
\text { He mentioned only the definition } \\
\text { of point-wise convergence. }\end{array}$ \\
\hline B & 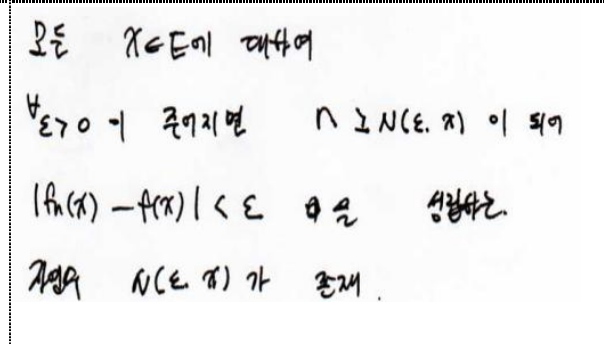 & $\begin{array}{l}\text { For the definitions of point-wise } \\
\text { convergence and uniform conver- } \\
\text { gence, the student B started with } \\
\text { 'each } x \text { ' and 'every } x \text { ', respective- } \\
\text { ly and wrote the same sentences } \\
\text { since then. So he stated only the } \\
\text { definition of point-wise conver- } \\
\text { gence. }\end{array}$ \\
\hline $\mathrm{C}$ & 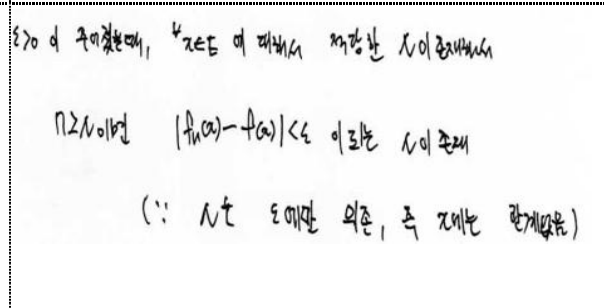 & $\begin{array}{l}\text { At first, the student } C \text { expressed } \\
N \text { depended on } x \text {, but finally, he } \\
\text { wrote } N \text { was independent of } x \text {. } \\
\text { ' } \forall x \text { ' for the uniform convergence } \\
\text { replaced 'each } x \text { ' for the point- } \\
\text { wise convergence at the same po- } \\
\text { sition. }\end{array}$ \\
\hline $\mathrm{D}$ & 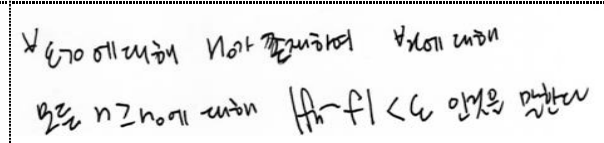 & $\begin{array}{l}\text { The student D stated the uniform } \\
\text { convergence exactly. }\end{array}$ \\
\hline $\mathrm{E}$ & 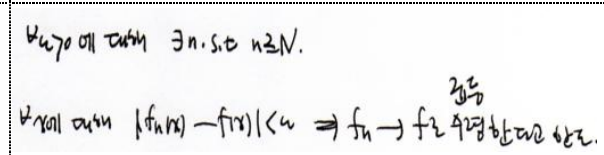 & $\begin{array}{l}\text { Instead of ' } \exists N \text { ', the student } \mathrm{E} \\
\text { wrote ' } \exists n \text { '. Except it, she under- } \\
\text { stood the definition exactly. }\end{array}$ \\
\hline $\mathrm{F}$ & 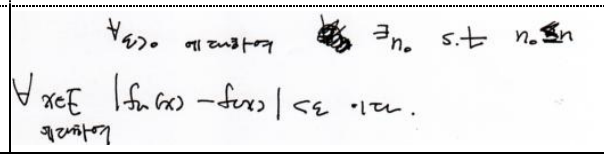 & $\begin{array}{l}\text { The student } F \text { corrected ' } n_{0} \geq n \text { ' by } \\
\text { ' } n_{0} \leq n \text { ' and rectified the location } \\
\text { of ' } \forall x \text { '. }\end{array}$ \\
\hline
\end{tabular}


For examples of point-wise convergence and uniform convergence of sequences of functions, female students D, E, and F considered the domain of functions as $\mathbb{R}$ unconditionally. Students D, E, and F did not recognize somewhat that the uniform convergence of a sequence of functions depends on the domain of functions in the sequence. However, female students D, E, and F found correct examples and it seemed that they understood the meaning of uniform convergence. They suggested functions with the term containing $n$ which is independent of the variable $x$.

The examples of uniformly convergent sequences of functions that students D, E, and F constructed are

$$
f_{n}(x)=\sin x+\frac{1}{n}, f_{n}(x)=x+\frac{1}{n}, \text { and } f_{n}(x)=\frac{1}{n}, \text { respectively. }
$$

They recalled the wavy image as personalized knowledge for uniform convergence. After they chose continuous functions, they set up the uniformly convergent sequences of functions waved with $\frac{1}{n}$ apart. Visual images of uniform convergence held in female students' minds seem to have the effects on the thought that their functions must converge to a function with uniform distance at all points. So, they made $f_{n}(x)$ by adding $\frac{1}{n}$ to a function $f(x)$ in order to control the speed of convergence at every point.

Table 6 shows how students described the definition of uniform convergence via examples of uniformly convergent sequences of functions.

Just like student $\mathrm{B}$, student $\mathrm{C}$ stated the definition of uniform convergence by changing only 'each $x$ ' for the definition of point-wise convergence to ' $\forall x$ ' at the same location. They didn't seem to think that ' $\forall x$ ' could mean 'each $x$ ' according to the location of it. The student $\mathrm{C}$ seemed to think of symbols ' $\forall x, \exists N$ ' as 'there exists $N$ for the whole'. It came from a lack of understanding of the symbol ' $\forall x$ '. Student $C$ was considered having a vague idea of the difference between the statements that $N$ depended on $x$ and $N$ was independent of $x$, but he treated the difference by expressing 'each $x$ ' and ' $\forall x$ ', respectively.

\subsection{Third questionnaire and analysis}

The third questionnaire in Table 7 was conducted to investigate students' understanding of the convergence of a sequence of continuous functions and the condition on continuity of the limit.

On the third questionnaire, male students $\mathrm{A}, \mathrm{B}$, and $\mathrm{C}$ tried to solve the problems without drawing graphs. On the other hand, except student E for Question 1, female students $\mathrm{D}, \mathrm{E}$, and $\mathrm{F}$ drew the graphs in order to know the uniform convergence. Female students tried to solve the problems with visual images in mind. 
Table 7. Third questionnaire - study on the convergence of sequences of continuous functions

Question 1. For $n \in \mathbb{N}$, let $f_{n}(x)=x^{n}, x \in[0,1]$.

1. Is $\left\{f_{n}\right\}$ a sequence of continuous functions on $[0,1]$ ?

2. Is the limit function $f$ continuous?

3. Does $\left\{f_{n}\right\}$ converge uniformly to $f$ on $[0,1]$ ?

4. Does $\left\{f_{n}\right\}$ converge uniformly to $f$ on $[0, r]$ for any $r, 0<r<1$ ?

5. Is the limit function $f$ continuous on $[0, r]$ for any $r, 0<r<1$ ?

Question 2. For $n \in \mathbb{N}$, let $f_{n}(x)=\frac{1}{n x}, 0<x<1$.

1. Is $\left\{f_{n}\right\}$ a sequence of continuous functions on $(0,1)$ ?

2. Is the limit function $f$ continuous?

3. Does $\left\{f_{n}\right\}$ converge uniformly to $f$ on $(0,1)$ ?

Table 8. Students' responses for Question 1

\begin{tabular}{|c|c|c|c|}
\hline Student & $\begin{array}{l}\text { Response for the uniform } \\
\text { convergence of }\left\{f_{n}\right\} \text { on }[0,1]\end{array}$ & Student & $\begin{array}{l}\text { Response for the uniform conver- } \\
\text { gence of }\left\{f_{n}\right\} \text { on }[0, r], 0<r<1\end{array}$ \\
\hline \multirow[b]{2}{*}{ A and D } & \multirow[t]{2}{*}{$\begin{array}{l}\text { Since } f \text { is discontinuous, } \\
\left\{f_{n}\right\} \text { is not uniformly conver- } \\
\text { gent. }\end{array}$} & A & $\begin{array}{l}\text { If } \epsilon=1 \text {, then }\left|x^{n}\right| \leq r^{n}<1=\epsilon \text { holds and } \\
\text { so }\left\{f_{n}\right\} \text { is uniformly convergent. }\end{array}$ \\
\hline & & $\mathrm{D}$ & $\begin{array}{l}\forall \in>0, \forall x \in[0, r], \text { let } \\
n_{0}=\log _{r} \in \text {. Then } \forall n \geq n_{0}, \mid x^{n}- \\
0 \mid<r^{n}<r^{n_{0}}=\epsilon \text { implies the uniform } \\
\text { convergence. }\end{array}$ \\
\hline B & $\begin{array}{l}\text { If } \epsilon=\frac{1}{2}, \text { then }\left|x^{n}\right|>\epsilon \text { and } \\
\text { so it is not uniformly conver- } \\
\text { gent. }\end{array}$ & B & $\begin{array}{l}\text { Since } 0<r<1 \text {, it is uniformly conver- } \\
\text { gent. }\end{array}$ \\
\hline $\mathrm{C}$ & $\begin{array}{l}\text { It is not uniformly convergent } \\
\text { (without saying any reason). }\end{array}$ & $\mathrm{C}$ & No answer \\
\hline \multirow[t]{2}{*}{$\mathrm{E}$ and $\mathrm{F}$} & \multirow{2}{*}{$\begin{array}{l}\text { Since } n \text { satisfying } \\
\left|f_{n}(x)-f(x)\right|<\epsilon \text { depends } \\
\text { on } x, \text { it is not uniformly con- } \\
\text { vergent. }\end{array}$} & $\mathrm{E}$ & $\begin{array}{l}\text { The limit function } f=0 \text { and } n \text { satis- } \\
\text { fying }\left|x^{n}\right|<\epsilon \text { depends on } x \text {. So it is } \\
\text { not uniformly convergent. }\end{array}$ \\
\hline & & $\mathrm{F}$ & $\begin{array}{l}\text { The limit function } f=0 \text { and so it is } \\
\text { uniformly convergent. }\end{array}$ \\
\hline
\end{tabular}

\section{1) Students' responses for Question 1}

Every student answered that $\left\{f_{n}\right\}$ was a sequence of continuous functions on $[0,1]$ 
and found the limit function $f$ correctly. But students $\mathrm{B}, \mathrm{E}$, and $\mathrm{F}$ thought that $f$ was continuous. They thought that the limit function of continuous functions should be continuous even though $f$ was obviously discontinuous. It is a commonly occurred error.

Students' responses for the uniform convergence of $\left\{f_{n}\right\}$ on $[0,1]$ and $[0, r], 0<r<1$ are in Table 8.

Student A claimed the uniform convergence of $\left\{f_{n}\right\}$ on $[0, r]$ by explaining the case when $\epsilon=1$. It is not a complete proof since only the special case with $\epsilon=1$ was explained. Student $\mathrm{D}$ got $n_{0}$ independent of $x$ and so it seemed that she knew that the sequence $\left\{f_{n}\right\}$ was uniformly convergent on $[0, r]$. But she did not use the symbol ' $\forall x \in[0, r]$ ' as 'for each $x$ in $[0, r]$ ', and she used it to explain $n_{0}$ 'for the whole domain $[0, r]$ '. Student D should have exchanged the locations of symbols ' $n_{0}=\log _{r} \epsilon$ ' and ' $\forall x \in[0, r]$ '.

Students $\mathrm{E}$ and $\mathrm{F}$ represented that they couldn't get $n_{0}$ independent of $x$ on $[0,1]$, but their explanations with symbols were insufficient. Student E didn't realize that the situation on $[0, r]$ was different from the situation on $[0,1]$. On the contrary, student $\mathrm{F}$ realized that the limit function on $[0,1]$ was different from the limit function on $[0, r]$. Especially, she knew that the limit function on $[0, r]$ was continuous, and then expected that the sequence of functions was uniformly convergent. We discovered that the prior knowledge on $[0,1]$ had an effect on the behavior of sequences of functions on $[0, r]$.

We see that the students put the geometrical intuitions about the fact that if the limit function $f$ is discontinuous, then the sequence $\left\{f_{n}\right\}$ of continuous functions is not uniformly convergent, into shape. It is usual with students to commit a fallacy such that a true proposition can be proved by taking an example as a wrong proposition can be proved false by taking a counterexample. In this research, student A also committed such fallacy.

\section{2) Students' responses for Question 2}

Every student answered that $\left\{f_{n}\right\}$ was a sequence of continuous functions on $(0,1)$ with the continuous limit function $f$. Except the student $\mathrm{F}$, every student said that $\left\{f_{n}\right\}$ was not uniformly convergent on $(0,1)$. To show that $\left\{f_{n}\right\}$ doesn't converge uniformly to $f$, we need to show the following statement:

$$
\exists \epsilon_{0}>0, \forall k \in \mathbb{N}, \exists n_{k} \geq k, x_{k} \in(0,1) \text { s.t. }\left|f_{n_{k}}\left(x_{k}\right)-f\left(x_{k}\right)\right| \geq \epsilon_{0} .
$$

As an answer for this question, we may write that there exists $\epsilon_{0}=1$,

$$
\forall k \in \mathbb{N}, \exists n_{k}=k, x_{k}=\frac{1}{k} \in(0,1) \text { such that }\left|f_{n_{k}}\left(x_{k}\right)-f\left(x_{k}\right)\right|=\left|\frac{1}{k \cdot 1 / k}-0\right|=1 \text {. }
$$


Students' responses for the uniform convergence of $\left\{f_{n}\right\}$ on $(0,1)$ are in Table 9.

Table 9. Students' responses for Question 2

\begin{tabular}{|c|c|}
\hline Student & Response for the uniform convergence of $f_{n}(x)=\frac{1}{n x}$ on $(0,1)$ \\
\hline A & $\begin{array}{l}\text { At } x=\frac{1}{2}, \exists n_{0} \in \mathbb{N},\left|\frac{2}{n_{0}}-0\right|>\frac{1}{n_{0}}=\epsilon \text {. If } \epsilon=\frac{1}{n_{0}} \text {, it is not uniformly con- } \\
\text { vergent. }\end{array}$ \\
\hline B & If $\epsilon=\frac{1}{n},\left|\frac{1}{n x}-0\right|=\frac{1}{n x}>\epsilon$ and so it is not uniformly convergent. \\
\hline $\mathrm{C}$ & It is not uniformly convergent (without saying any reason). \\
\hline $\mathrm{D}$ & $\begin{array}{l}\text { It is not uniformly convergent since } n \text { depends on } x \\
\text { (without saying concrete explanation). }\end{array}$ \\
\hline $\mathrm{E}$ & $\begin{array}{l}\text { Since } \frac{1}{\mathrm{x}}>1, \quad\left|\frac{1}{n x}\right|>\frac{1}{n} \text {. Since } \epsilon \text { satisfying }\left|\frac{1}{n x}\right|<\epsilon \text { depends on } \mathrm{n} \text { and } x \text {, it } \\
\text { is not uniformly convergent. }\end{array}$ \\
\hline $\mathrm{F}$ & It is uniformly convergent (without saying reason). \\
\hline
\end{tabular}

Students A, B, and E made mistakes in using symbols to show non uniform convergence, but they at least tried to find a specific $\epsilon$. In the students' responses to Question 2, we can clearly see that students made errors such as that if the limit function is continuous, then the given sequence of functions is uniformly convergent regardless of the given domain.

\subsection{Fourth questionnaire and analysis}

The fourth questionnaire in Table 10 was conducted to study students' visual images for the point-wise convergence and the uniform convergence.

Table 10. Fourth questionnaire - visual images on convergences of sequences

Question. Describe the point-wise convergence and the uniform convergence of a sequence of continuous functions visually. What is your own image for these kinds of convergence? For example, when we study the 'Converse of the Proposition', we understand the concept 'converse' from the come-from-behind-victory or flowing backward. Write your own metaphor for two kinds of convergence.

Through Table 11, we can see that students have personalized images by metaphor for the point-wise convergence and the uniform convergence of a sequence of continuous functions. 
Table 11. Students' responses for the fourth questionnaire

\begin{tabular}{|c|c|c|}
\hline Student & $\begin{array}{l}\text { Description of the point-wise conver- } \\
\text { gence }\end{array}$ & $\begin{array}{l}\text { Description of the uniform con- } \\
\text { vergence }\end{array}$ \\
\hline A & $\begin{array}{l}\text { Like stairs. Since } n \text { varies by } x \\
\text { with the point-wise convergence, } \\
\text { when numbering stairs by } x, \text { the in- } \\
\text { terval changes by } x \text {. }\end{array}$ & $\begin{array}{l}\text { Love of parents. It looks like to } \\
\text { tolerating every } x \text { within } \in \text { dis- } \\
\text { tance for some } n \text {. }\end{array}$ \\
\hline $\mathrm{B}$ & $\begin{array}{l}\text { The point-wise convergence is like } \\
\text { having two best friends. For each } \\
\text { point } x \text {, they are } n \& . \epsilon \text {. }\end{array}$ & $\begin{array}{l}\text { The uniform convergence is like } \\
\text { having only one best friend. }\end{array}$ \\
\hline $\mathrm{C}$ & $\begin{array}{l}\text { For each point, } n_{i} \text { 's are gathered and } \\
\text { it is shaped like a magic club. }\end{array}$ & $\begin{array}{l}\text { For given } \epsilon, \exists n_{0} \text { and a limit } \\
\text { function } f \text { so that it is shaped } \\
\text { like a lake. It is like a bent wire. }\end{array}$ \\
\hline $\mathrm{D}$ & Point by point convergence is needed. & $\begin{array}{l}\text { Functions gather near a limit func- } \\
\text { tion at every point. }\end{array}$ \\
\hline $\mathrm{E}$ & $\begin{array}{l}\text { For each point, } \exists \epsilon \text { interval (Figure } \\
5 \text { ). }\end{array}$ & $\begin{array}{l}\text { For given } \epsilon \text { for } f \text {, it converges at } \\
\text { every point (Figure 6). }\end{array}$ \\
\hline $\mathrm{F}$ & $\begin{array}{l}\text { For each point, we can find an inter- } \\
\text { val of convergence. }\end{array}$ & $\begin{array}{l}\text { For some intervals, it converges } \\
\text { for every point in the interval. }\end{array}$ \\
\hline
\end{tabular}

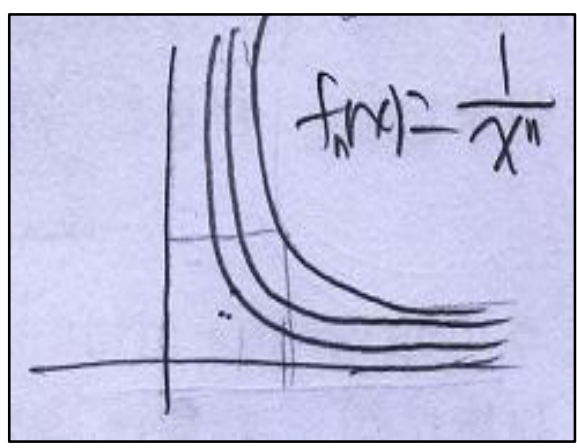

Figure 5. Point-wise convergence by student $\mathrm{E}$

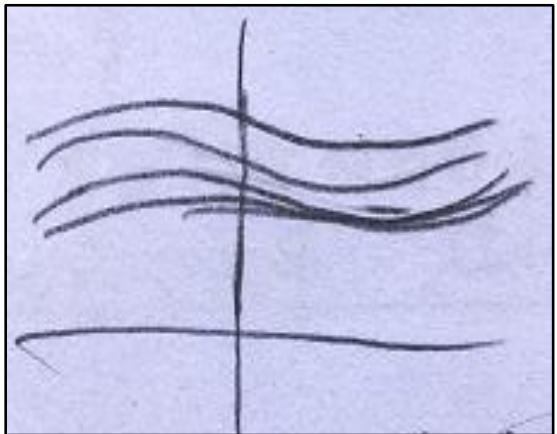

Figure 6. Uniform convergence by student $\mathrm{E}$

\section{Analysis of the difference between the views of male and female students}

For our research, we divided the students into two groups, a group of male students and a group of female students. From the analysis of the first questionnaire about the understanding of concepts, it was found that male students tried a geometric approach more often than female students did. However, from the second questionnaire study, we can see 
that female students committed fallacies less than male students in the geometric explanation of the concept image concerning sequences of continuous functions.

Male students $\mathrm{A}$ and $\mathrm{C}$ described point-wise convergence with the $\epsilon-N$ definition of limit only. The student B did it with the $\epsilon-N$ definition of limit and a graph showing the point-wise convergence. Also, he drew another graph of wavy shape representing the uniform convergence (Figure 3). On the other hand, all of the female students drew graphs first and then described point-wise convergence with the $\epsilon-N$ definition of limit (Figure 4). Interestingly, while remembering the concept image via figures, female students described convergence formally.

Also, for examples of the uniform convergence, each female student set up a continuous function and constructed a sequence of functions by adding $\frac{1}{n}$ to the function for wavy shape. They had a concept image that, as a visual image of the uniform convergence, the sequence of functions should have approached a limit with the uniform distance. In the second questionnaire, male students indicated the domains of point-wise convergent sequences of functions and uniformly convergent sequences of functions concretely while female students thought of the domains of them as the set of real numbers unconditionally and did not pay attention to the domains. Female students did not consider the fact that the uniform convergence depends on the domain. Female students tried a geometric approach more than male students in the third questionnaire.

\section{RESULTS}

In this research we have done case studies to examine and analyze how students arrived at the $\epsilon-N$ proof via geometrical intuition. We developed the questionnaires stage by stage, and then carried out the surveys four times, before analyzing the research results to give us an accurate idea of how students conceptualized both continuous functions and sequences of continuous functions. These are areas that are typically difficult for students while studying Advanced Calculus and General Topology. As a result of this research, we have some suggestions on how to improve the teaching and learning methods regarding the convergence of continuous functions.

Through this research, we have identified some mathematical misconceptions about the point-wise convergence and the uniform convergence that students hold. When students' concept images are expressed through discussion or presentation in the regular class, learned knowledge can be updated. Similarly, students can nourish the democratic citizenship to accept various thoughts by experiencing community life via discussion. This is one of the goals of mathematics education (Kim, Park \& Woo, 2007). 
The fallacies that students committed in this questionnaire study are as follows: First, students showed a lack of understanding of the symbol ' $\forall x$ '. In the second and third questionnaires, students thought that the difference between the point-wise convergence and the uniform convergence was to write 'each $x$ ' and ' $\forall x$ ' in the same place of the definition, respectively (students B and $\mathrm{C}$ of Table 6 , student $\mathrm{D}$ of Table 8). They did not pay attention to the location of the symbol ' $\forall x$ ' for the uniform convergence and they thought of the symbols ' $\forall x, \exists N$ ' as 'there exists $N$ for the whole domain'. In some sense, this can be seen as a result of the differences in word order between Korean and English. Second, students thought that if the limit function was continuous, then the sequence of continuous functions must be uniformly convergent. Students tended to think that the sequences of functions converge uniformly regardless of the domain of sequences of functions. Third, students tried to prove a true proposition by taking an example as a false proposition could be proved by taking a counterexample. It is a common mistake that a true proposition can be proved by taking an example, and we confirm such a tendency in this research. Finally, students demonstrated a lack of internalization of logical expression when they used mathematical symbol and did verbal justification. They mistakenly used the word 'because ...' when they should have said 'in order to ...'.

\section{SUGGESTION}

Based on the results of this questionnaire study, we suggest the following: First, various easy examples must be practiced for students to understand the symbol ' $\forall x$ ' completely. Second, since students know that if a sequence of continuous functions is uniformly convergent, then the limit function is continuous, they assume that the converse is also true and hence a sufficient explanation of the conditions needed for a converse proposition to be valid is needed. Third, the internalization by examples is needed for the fact that false propositions can be shown using a counterexample, but true propositions cannot be proved by an example. Fourth, students should be trained in order not to make logical fallacies when they use mathematical symbol and do verbal justification. Finally, emphasis should be placed on the importance of checking the domain of functions at any time.

As in the fourth questionnaire, students represented various concept images about the point-wise convergence and the uniform convergence. Appropriate visual examples will help students to attain concept definition of point-wise convergence and uniform convergence. However, as Hwang \& Shim (2010) assert, such geometric intuition can cause intuitive obstacle. A concrete teaching strategy should be used to overcome this issue. As a teaching method for a proper balance between formal analysis and intuitive analysis of 
the concept, Lee \& Park (2001) suggested harmony of intuition and logic, overcoming the phenomenon of functional fixation, development of useful intuitive model, development of meta-cognitive ability, and so on. Practice of strict formal inference is a necessary mental training exercise in order to attain the concept definition via the process of depersonalization beyond the concept image. Sufficient time for understanding thoughts, ideas, symbols, and concepts shared through small group discussion with peers can be a good teaching method in the process of depersonalization as well as personalization.

\section{REFERENCES}

Brown, J. R. (1999). Philosophy of Mathematics-An Introduction to the World of Proofs and Pictures. London: Routledge. ME 2000d.02450

Cho, C.-S. (2011). Exploring a teaching Method of Limits of Functions with Embodied Visualization of CAS Graphing Calculators. Communications of Mathematical Education 25(1), 63-78

Dieudonne, J. (1969). Foundations of Modern Analysis. New York: Academic Press.

Hwang, H. J.; Na, G. S.; Choi, S. H.; Park, K.; Yim, J. \& Seo, D. Y. (2011). New Theory of Mathematical Education. Seoul: Moonumsa.

Hwang, S. \& Shim, S. K. (2010). A Study on Students' Responses to Non-routine Problems Using Numerals or Figures (in Korean). J. Korea Soc. Math. Ed. Ser. A, Math. Educ. 49(1), 39-51. ME 2011b.00215

Kim, E. H. (2011). Study on Point-wise and Uniform Convergence of Function Sequences and Series. Dissertation of Master Degree. Kimhae: Inje University.

Kim, E. T.; Park, H. S. \& Woo, J. H. (2007). An Introduction to Mathematical Education. Seoul: Seoul National University Press.

Lee, D.-H. \& Park, B.-H. (2001). A Study on Intuition and Its Fallacy in Mathematics Education (in Korean). J. Korea Soc. Math. Ed. Ser. A, Math. Educ. 40(1), pp. 15-25. ME 2001d.03015

Munkres, J. R. (1975). Topology: a Fist Course. New Delhi: Prentice Hall.

Park, S. H. (1993). A study on cognitive conflicting factors occurring in concept instructions. Journal of Educational Research in Mathematics 3(1), 185-194.

Seo, Y. O. (2001). Point-wise convergence and uniform convergence of a sequence of functions. Dissertation of Master Degree. Seoul: Yonsei University.

Stoll, M. (2001). Introduction to Real Analysis (2nd Ed). Boston: Addison-Wesley Longman, Inc.

Vinner, S. (1983). Concept Definition, Concept Image and the Notion of Function. Int. J. Math. Educ. Sci. Technol. 14(3), 293-305. ME 1984a.10119

Woo, J. H. (2005). Educational Basis on School Mathematics. Seoul: Seoul National University Press. 